Revista Española de Derecho Internacional Sección PRÁCTICA ESPAÑOLA DE DERECHO INTERNACIONAL Vol. 70/1, enero-junio 2018, Madrid, pp. 285-294 http://dx.doi.org/10.17103/redi.70.1.2018.3.02 (C) 2018 Asociación de Profesores de Derecho Internacional y Relaciones Internacionales ISSN: 0034-9380; E-ISSN: 2387-1253

\title{
LA «CUESTIÓN CATALANA»
}

\author{
Antonio Remiro Brotons* \\ Paz ANDRÉs SÁENZ DE SANTA MaRÍA**
}

SUMARIO: 1 . INTRODUCCIÓN.-2. DEMOCRACIA.-3. DIÁLOGO.-4. LA DECLARACIÓN DE INDEPENDENCIA.-5. LA APLICACIÓN DEL ART. 155 DE LA CONSTITUCIÓN.6. LA APLICACIÓN DE LA LEY PENAL Y LA EUROORDEN.-7. LA DECLARACIÓN DE INDEPENDENCIA EN EL ORDEN INTERNACIONAL: EFECTIVIDADES EN ACCIÓN.-8. EL RECONOCIMIENTO DE LA INDEPENDENCIA POR TERCEROS.

\section{INTRODUCCIÓN}

El 18 de septiembre de 2017, ante la errónea invocación del Derecho Internacional (DI) para dotar de fundamento jurídico a la Ley del Referéndum de autodeterminación aprobada por el Parlament de Cataluña el día 6 del mismo mes, más de 400 miembros de la Asociación Española de Profesores de Derecho Internacional y Relaciones Internacionales entendieron que era su obligación cívica suscribir y difundir una declaración escueta, clara, rigurosa y asequible al lector no especializado, cuyo texto figura a continuación de esta nota, en la que se concluía que Cataluña no era una entidad que disfrutase de un derecho de separación del Estado reconocido por el DI y, por tanto, el derecho de libre determinación no podía constituir el fundamento jurídico para consultar a los ciudadanos sobre su independencia, como pretendía la citada Ley del Referéndum, primero suspendida y finalmente anulada por el Tribunal Constitucional en Sentencia unánime de 17 de octubre de 2017, por su manifiesta inconstitucionalidad.

Los hechos ocurridos desde esas fechas hasta entonces, particularmente a partir del 1 de octubre en que se realizó de facto, que no de iure, una consulta popular, desprovista de toda clase de garantías y con incidentes de orden público, han atraído el interés de un buen número de iusinternacio-

* Catedrático Emérito de Derecho internacional público y relaciones internacionales. Universidad Autónoma de Madrid. Miembro de l'Institut de Droit International (antonio.remiro@gmail.com).

** Catedrática de Derecho internacional público y relaciones internacionales en la Universidad de Oviedo(pandres@uniovi.es). 
nalistas, que se han pronunciado sobre la que podemos llamar la cuestión catalana.

En términos generales, las opiniones vertidas suelen coincidir con la declaración de los especialistas españoles en la expresión de las normas vigentes del Derecho internacional sobre los supuestos del derecho de libre determinación, sus titulares y sus límites; pero cuando se trata de su aplicación a las pretensiones independentistas en Cataluña se leen consideraciones que sugieren que sus autores ignoran o desdeñan el hecho básico de que España es un Estado democrático, cuyo ordenamiento jurídico se desarrolla en el marco de una Constitución cuyo respeto cuenta con la garantía de un Tribunal Constitucional, y se rige por un principio de separación de poderes. Solo así se explica que se atrevan a apuntar que la secesión de Cataluña como remedio a una violación grave de derechos fundamentales de su población no estaría justificada por ahora.

\section{DEMOCRACIA}

Se dice que negar el derecho a decidir de los catalanes sobre su propio futuro es intrínsecamente antidemocrático. Sin embargo, democracia, que traducido literalmente del griego significa poder (cratos) del pueblo (demos), requiere una previa identificación del pueblo al que se atribuye la titularidad de ese poder. En el Estado soberano el principio democrático atribuye a la población en su conjunto esa titularidad. Así ocurre en España conforme a la Constitución en vigor. Son los ciudadanos españoles, incluidos naturalmente los catalanes, los que gozan del derecho a decidir su futuro, a determinar libremente su destino, a adoptar uno u otro sistema político, económico y social. Lo antidemocrático sería, pues, usurpar al resto de españoles un derecho que les pertenece y que ejercerán oportunamente si se presenta a su decisión vinculante una reforma constitucional en los términos previstos en el Título X de la vigente Constitución ${ }^{1}$.

La democracia, por otro lado, no es la premisa de los derechos y libertades de individuos y grupos humanos, sino su consecuencia. Sin el respeto del Estado de Derecho, de la ley, no hay democracia.

\section{DIÁlOGO}

Diálogo es una bella palabra, que penetra con su aroma civilizado en el tuétano de los conflictos para evitar salidas o soluciones violentas. Sin embargo,

\footnotetext{
1 Asimismo, dentro del Capítulo II del Título III, el art. 92 prevé la posibilidad de someter «decisiones políticas de especial trascendencia [...] al referéndum consultivo de todos los ciudadanos». Las condiciones y procedimientos de las distintas modalidades de referéndum previstas por la Constitución son reguladas por la Ley Orgánica 2/1980, de 18 de enero, modificada por la Ley Orgánica 12/1980, de 16 de diciembre (BOE núm. 20, de 23 de enero de 1980).
} 
algunas de las propuestas expresadas en torno a la cuestión catalana buscan transformar la relación vertical de las partes en el marco constitucional en una relación horizontal o paritaria, de poder a poder, al margen de la ley o, mejor, contra la ley. Implican el reconocimiento del hecho revolucionario y la inevitable consumación de sus efectos. No tienen por objeto reconducir sus pretensiones dentro del Estado de Derecho que ha venido violentando sino, por el contrario, consolidar la secesión negociando con el Gobierno central una sucesión pactada. Reclamar una mediación internacional es el colofón de esta pirueta.

Es obvio que si el Gobierno del Estado no podía constitucionalmente convocar o autorizar la convocatoria por la Generalitat de un referéndum de los ciudadanos residentes en Cataluña para decidir si permanecían en España o se separaban de ella, aún puede menos dialogar sobre la supervivencia del todo con una parte de ella, infringiendo las normas fundamentales del orden constitucional.

En cambio, el diálogo puede llegar hasta una reforma constitucional que, por hipótesis, haga del pacto entre diferentes naciones fundamento legitimador del Estado y admita, como consecuencia, un derecho de secesión como expresión de la autodeterminación de cada una de ellas. Pero eso será así cuando la Ley Fundamental se reforme siguiendo los cauces dispuestos para ello. Hasta entonces, es obligado el acatamiento de la Constitución para entablar un diálogo formal.

\section{LA DECLARACIÓN DE INDEPENDENCIA}

¿Se produjo o no la declaración de independencia de Cataluña en la sesión extraordinaria del Parlament del 10 de octubre, convocada a petición del Presidente de la Generalitat para explicar la situación en Cataluña tras el referéndum del 1 del mismo mes y los hechos que le siguieron? Conviene advertir que, sorprendentemente, el Parlament no había desarrollado actividad alguna desde el 7 de septiembre anterior cuando bien entrada la noche aprobó la ley de transitoriedad que debía ordenar la desconexión de Cataluña respecto del resto de España.

El discurso del Sr. Puigdemont alimentó toda suerte de interpretaciones contradictorias y, como consecuencia, vino a justificar el primero de los requerimientos que le formuló el Gobierno central el 11 de octubre. La confusión se debió al hecho de que tras una primera afirmación interpretada pacíficamente como una declaración de independencia, el Sr. Puigdemont anunció que solicitaba del Parlament la suspensión de los efectos de la declaración, a fin de ofrecer una oportunidad al diàleg con el Estado para alcanzar una «solución acordada». La respuesta del Presidente de la Generalitat a los requerimientos del Gobierno el día 16 no fue sí ni no. Y tampoco la del 19 vino a aclarar definitivamente las cosas.

Ateniéndonos a los cánones de la recta interpretación, no cabe suspender los efectos de una declaración a menos que esta haya sido hecha. Por añadi- 
dura, el Parlament no se pronunció sobre la solicitud del presidente. E, ítem más, levantada la sesión extraordinaria, en una sala aneja, 72 diputados suscribieron con luz y taquígrafos una extensa declaración de independencia en ninguna de cuyas cuatro páginas volvía a hacerse mención alguna de la suspensión de sus efectos. Recordemos, por último, que conforme al art. 4 de la Ley del Referéndum, una vez proclamados sus resultados y sumando los síes más que los noes, era preceptivo declarar la independencia en cuarenta y ocho horas. No obstante, ese mismo precepto atribuía al Parlament la satisfacción de esa obligación, lo que en ese momento no hizo.

Sea como fuere, y en medio de la tensión generada por la decisión del Gobierno de solicitar del Senado la aprobación de las medidas que, conforme al art. 155 de la Constitución, podían facultarle para obligar a las instituciones de la Generalitat de Cataluña al cumplimiento de sus obligaciones y a proteger un interés general gravemente conculcado por estas, el Parlament declaró formalmente la independencia el 27 de octubre.

Parece bizantino que tirios y troyanos hayan ocupado su tiempo deliberando sobre si esta declaración se hizo, sobre cuándo se hizo y sobre sus efectos jurídicos. Las declaraciones de independencia son la guinda en el pastel del hecho revolucionario y, como tales, son desde un punto de vista constitucional, radicalmente antijurídicas, nulas. Que se produzcan en el marco de una sesión parlamentaria no las dota de un carácter del que carecen por su misma naturaleza; más bien, agrava su antijuridicidad. Ciertamente, no es lo mismo declarar la independencia en un Parlament que, por ese mismo hecho, se transfigura en otra cosa, que hacerlo en un casino.

\section{LA APLICACIÓN DEL ART. 155 DE LA CONSTITUCIÓN}

Junto con el recurso al art. 155 de la Constitución, el Gobierno pudo - y puede- acudir a otras bases legales, en la misma Constitución, como el art. 116, o en leyes, como la de Seguridad Nacional, para adoptar medidas frente a la grave situación creada por la sistemática deslealtad constitucional de la Generalitat. No obstante, el art. 155 de la Constitución ha centrado el interés público por calzar como un guante en el supuesto que estamos examinando.

De acuerdo con el numeral 1 del art. 155 de la Constitución, un precepto directamente inspirado en la Ley Fundamental de la República Federal de Alemania (art. 37) y más tibio que la disposición prevista por la Constitución italiana (art. 126) para situaciones semejantes:

«Si una Comunidad Autónoma no cumpliere las obligaciones que la Constitución u otras leyes le impongan, o actuare de forma que atente gravemente al interés general de España, el Gobierno, previo requerimiento al Presidente de la Comunidad Autónoma y, en el caso de no ser atendido, con la aprobación por mayoría absoluta del Senado, podrá adoptar las medidas necesarias para obligar a aquella al cumplimiento forzoso de dichas obligaciones o para la protección del mencionado interés general». 
El Gobierno, que había llamado reiteradamente al orden al presidente de la Generalitat y recurrido ante el Tribunal Constitucional los sucesivos actos del Govern y del Parlament de Cataluña - declarados inconstitucionales por el Tribunal sin que se le hiciera el menor caso- acordó poner en marcha el art. 155 de la Constitución y, tras considerar insatisfactoria la respuesta del Presidente de la Generalitat al doble requerimiento que le había dirigido, solicitó del Senado el 21 de octubre su preceptiva aprobación (por mayoría absoluta) de las medidas que entendía necesarias para obligar a la Comunidad Autónoma al cumplimiento forzoso de sus obligaciones y proteger el interés general del Estado.

El art. 189 del Reglamento del Senado regula el procedimiento aplicable al caso con un espíritu claramente garantista de la defensa de la Comunidad Autónoma disconforme con la iniciativa del Gobierno central.

En primer lugar, porque descarta el «factor sorpresa», pues la alabada generalidad con que se pronuncia la Constitución al dejar en manos del Gobierno la determinación de las medidas que considere «necesarias» para forzar la mano de instituciones autonómicas rebeldes se acaba en cuanto se inicia la tramitación en el Senado, ya que el Gobierno ha de manifestar «el contenido y alcance de las medidas propuestas», sin que quepa solicitar un cheque en blanco.

En segundo lugar, porque tanto en Comisión (en este caso una Comisión Conjunta de la Comisión General de las Comunidades Autónomas y de la Comisión Constitucional), como en el Pleno, el Presidente de la Comunidad Autónoma implicada cuenta con medios para oponerse a la aprobación de las medidas propuestas. En Comisión, porque se le requiere la remisión de antecedentes, datos y alegaciones que estime pertinentes, pudiendo designar un representante a tales efectos; en el Pleno, porque la propuesta razonada de la Comisión (que puede condicionar o modificar las medidas proyectadas) se somete a debate con dos turnos a favor y dos en contra y las intervenciones de los portavoces de los grupos parlamentarios que lo soliciten.

Aunque el procedimiento se evacuó con la rapidez que requería la situación, el trámite consumió seis días, de manera que fue el 27 de octubre, coincidiendo con la declaración de independencia aprobada por el Parlament, cuando el Pleno del Senado aprobó las medidas propuestas, previamente pactadas por los llamados partidos «constitucionalistas», a saber, el PP, el PSOE y Ciudadanos.

La aplicación del art. 155 de la Constitución ponía al Estado rumbo a lo desconocido. Se entiende la desgana del Gobierno en tener que acudir a él y hacerlo finalmente arrastrando los pies, tras dar sucesivas oportunidades a la Generalitat para rectificar y restablecer el orden constitucional y estatutario. Se proponía el cese del Presidente, Vicepresidente y Consejeros del Govern, la asunción temporal de sus competencias por los Ministros del Gobierno central en el ramo correspondiente, la limitación de las competencias del Parlament en la medida en que pudiese derivar en un ejercicio inconstitucio- 
nal y la atribución al Presidente de Gobierno de la facultad de disolverlo para facilitar elecciones que se preveían en un plazo máximo de seis meses. Finalmente, obtenida la aprobación del Senado, el Consejo de Ministros decidió al día siguiente, 28 de octubre, las medidas señaladas, con la inesperada decisión de la inmediata disolución del Parlament y la convocatoria de elecciones autonómicas el 21 de diciembre.

Hay quienes han pretendido demonizar el art. 155 de la Constitución. El Govern trató, inútilmente, de frenar su aplicación recurriendo ante el Tribunal Constitucional. Luego, tanto el Sr. Puigdemont como otros voceros, dentro y fuera de Cataluña, han repetido hasta el cansancio que el Estado había dado un golpe de estado, una afirmación sin fundamento. Las medidas adoptadas pueden ser objeto de la crítica política, pero no de una censura de inconstitucionalidad.

En nuestra opinión, estas medidas eran proporcionadas a la gravedad de la situación y la contumacia de los miembros del Govern, de la Mesa y de la mayoría independentista en el Parlament en el desacato de las decisiones del Tribunal Constitucional y en el quebrantamiento sistemático de la Constitución y del Estatuto de Autonomía. Tenían su lógica, pues sería poco realista considerar que quienes son los responsables del desastre y se empecinaban en él iban a someterse a las «instrucciones» del Gobierno para deshacer sus propios entuertos. Implicaban, a su vez, una intervención mínima, por un doble motivo. La intervención, en efecto, no afectaba a la estructura y funcionamiento de la Administración, incluida la policía de la Generalitat (los Mossos d'Esquadra), fuerza en la que, simplemente, se cesó a su Major, sometido ya a investigación judicial, siendo sustituido por su segundo. Por otro lado, la convocatoria de elecciones en la fecha más inmediata posible conforme a las normas estatutarias, había de significar la terminación de la aplicación de las medidas acordadas por el Gobierno.

Cabe, pues, hablar de una gradualidad en la adopción de medidas necesarias para satisfacer el objetivo irrenunciable: salvaguardar la unidad indisoluble de la Nación (art. 2) y la soberanía del pueblo español (art. 1.2). Esos objetivos son permanentes mientras no se reforme la Constitución en otro sentido, por lo que el Govern y la mayoría parlamentaria que pueda sustentarlo tras las elecciones del 21 de diciembre podrán en su caso, si tienen un cariz independentista, sostener políticas de reforma constitucional que den cauce a sus pretensiones, pero no reiterar acuerdos y decisiones que han forzado la aplicación del art. 155 de la Constitución en la forma menos invasiva a una comunidad cuya autonomía ha sido violentada por quienes han corroído, al hacerlo, las bases de su propia legitimidad. El art. 155 no desaparece del universo constitucional el 21 de diciembre. Es deseable que no deba ser invocado de nuevo. 


\section{LA APLICACIÓN DE LA LEY PENAL Y LA EUROORDEN}

Apreciando el carácter presuntamente delictivo de los actos y acuerdos tomados por los miembros del Govern y de la Mesa del Parlament, la Fiscalía General del Estado se querelló contra todos ellos, imputándoles los delitos de rebelión, sedición, malversación de caudales públicos y desobediencia, entre otros. Los miembros del Govern cesados el 28 de octubre, no aforados, fueron citados el 31 a declarar ante la juez de instrucción de la Audiencia Nacional el 2 de noviembre. En las mismas fechas la Presidenta y miembros de la Mesa del Parlament, aforados, lo fueron ante un magistrado de la Sala Penal del Tribunal Supremo, que suscitó la posibilidad de rebajar la rebelión a «conspiración» para la rebelión.

En una nota de estas características no podemos entrar en los complejos problemas procesales que se plantean en un caso que, finalmente, ha sido asumido por la Sala de lo Penal del Tribunal Supremo. Es un hecho que el ex-President Puigdemont y cuatro de sus consellers no acudieron a la citación judicial el 2 de noviembre y optaron por permanecer en Bruselas, adonde se habían desplazado dos días antes. El Vicepresidente Junqueras y los otros miembros del Consejo sí lo hicieron y tras negarse a contestar a otras preguntas que no fueran las de sus abogados, la juez de instrucción dictó prisión provisional incondicional para todos, salvo uno, que pudo eludirla mediante fianza de 50.000 euros. La Presidenta del Parlament y los miembros de la Mesa, en el Supremo, obtuvieron el aplazamiento de una semana para prestar declaración, solicitado para la mejor preparación de sus defensas. El 9 de noviembre, todos ellos se allanaron al acatamiento de la Constitución y al respeto de la aplicación del art. 155, lo que puede explicar que la Sra. Forcadell, Presidenta del Parlament, haya podido eludir la prisión mediante fianza de 150.000 euros y que los demás miembros de la Mesa hayan debido abonar fianzas muy inferiores, de 25.000 euros, o incluso, uno de ellos, salir de la sede del Tribunal Supremo en libertad sin medida cautelar alguna.

El calculado desplazamiento a Bruselas del ex-President Puigdemont y cuatro de sus consellers dio lugar, por otro lado, a la emisión de las correspondientes órdenes europeas de detención y entrega, lo que nos colocó en el terreno de la cooperación jurídica internacional basada en la confianza mutua entre los sistemas judiciales de dos Estados miembros de la Unión Europea (UE) como países democráticos, que se materializa a través de un procedimiento en el que se garantiza el respeto de los derechos humanos, pero esta situación judicial adquirió un nuevo giro cuando el magistrado instructor de la causa en el Tribunal Supremo decidió retirar la euroorden para evitar distorsiones entre los títulos de imputación de los fugados y los de los que sí atendieron la citación de la justicia española.

Desde Bruselas el antiguo president y otros afines al procés separatista han hablado de "presos políticos» y reclamado su libertad. El error es deliberado. En un Estado democrático no hay «presos políticos». La motivación política 
ínsita en los delitos de que se acusa a tales presos no exime de responsabilidad penal a quienes cumplen el tipo delictivo, que es lo que ha de probarse. Los conflictos políticos reclaman soluciones políticas, cierto. Pero las sanciones penales deben aplicarse a los políticos que delinquen, a menos que se pretenda que su impunidad forma parte de las soluciones políticas.

El Sr. Puigdemont insiste en su legitimidad como presidente de la Generalitat, pasando por alto que la perdió al destruir conscientemente sus bases constitucionales y estatutarias. En un Estado democrático no se debe oponer a la ligera legitimidad y legalidad. El respeto de la ley es la garantía más firme de la legitimidad de ejercicio. La legitimidad de origen no es invulnerable cuando se quebranta sistemáticamente la legalidad.

\section{LA DECLARACIÓN DE INDEPENDENCIA EN EL ORDEN INTERNACIONAL: EFECTIVIDADES EN ACCIÓN}

¿Qué cabe decir de las declaraciones de independencia en el orden internacional? Ya hemos puesto blanco sobre negro que el derecho de secesión como expresión de la autodeterminación de un pueblo interesa a supuestos muy ajenos al catalán. La independencia de Cataluña podrá ser un hecho, pero no el resultado del ejercicio de un derecho que no reconoce, amén de la Constitución del Estado, el DI.

Se ha sacado de contexto la Opinión Consultiva de la Corte Internacional de Justicia de 22 de julio de 2010, que por 10 votos contra cuatro consideró que la declaración unilateral de independencia de Kosovo, de 17 de febrero de 2008, no había violado ninguna regla aplicable de DI. Para la Corte, sencillamente, la declaración era, en las circunstancias del caso, un mero hecho carente en sí mismo de relevancia jurídica. No era la primera vez, por otro lado, que los albano-kosovares declaraban la independencia de la provincia autónoma de Serbia. Probablemente era a esto a lo que se refería la Vicepresidenta del Gobierno al afirmar que, a fin de cuentas, una declaración de independencia sería inefectiva, lo que está por ver. Urgida por su situación procesal, la Presidenta del Parlament ha afirmado en sede judicial que la declaración de independencia del 27 de octubre era solo simbólica.

En efecto, una declaración de independencia es una expresión de voluntad que ha de ser confirmada por las obras, esto es, por su efectividad. Una declaración de independencia no se mide por el rasero del Derecho, sino por el de sus efectividades en acción, el ejercicio de competencias soberanas, el control del territorio. La efectividad de una declaración de independencia es la premisa sin la cual quien se pretende Estado soberano carece de sustentación. 


\section{EL RECONOCIMIENTO DE LA INDEPENDENCIA POR TERCEROS}

Se ha discutido si el reconocimiento de la condición soberana de un Estado por otros Estados y Organizaciones Internacionales compuestas por Estados soberanos es constitutivo o solo declarativo de su condición de sujeto de Derecho internacional. En todo caso, aun declarativo, el papel del reconocimiento es extraordinariamente relevante. Sin reconocimiento el Estado, aun soberano, es hasta cierto punto un Estado robinsoniano. Cierto que podrá desarrollar alguna actividad exterior, especialmente de índole comercial y de promoción turística y cultural, a través de oficinas sometidas al Derecho interno del país en el que se localizan. Pero no podrá establecer relaciones diplomáticas ni consulares en sentido estricto, suscribir tratados, reclamar inmunidad en foros extranjeros o ser miembro de Organizaciones intergubernamentales. Tampoco podrá expedir pasaportes como documentos de viaje a menos que medie su reconocimiento.

El reconocimiento es un acto subjetivo al que se trata de dotar de parámetros objetivos. No cabe reconocer a quienes reclaman la condición de Estado soberano cuando no controlan efectivamente un territorio y cuentan con instituciones democráticas que representan a la población en su conjunto. Hacer tal cosa sería un acto de injerencia en un asunto interno del Estado cuya integridad es desafiada. Lamentablemente, no faltan los casos de reconocimientos que podemos llamar prematuros en el que un Estado ve en otro una efectividad avant la lettre. Alemania, por ejemplo, actuó así en el reconocimiento de Eslovenia y de Croacia en el proceso de descomposición de Yugoslavia. Y la Santa Sede fue de la mano con Alemania, arrastrando a todos los miembros de la UE. Pero Yugoslavia no era miembro de la Unión.

Como el reconocimiento es un acto descentralizado, el quantum operativo de la subjetividad internacional del Estado dependerá del número y calidad de los Estados y Organizaciones intergubernamentales que lo reconozcan. El desideratum de todo Estado nuevo es ingresar en la Organización de las Naciones Unidas, pues su universalidad y el procedimiento de admisión garantizan el más amplio reconocimiento, incluido el de las Grandes Potencias.

El reconocimiento del Estado nuevo altera sustancialmente las reglas de juego. Transforma en fuerzas de ocupación las del Estado viejo y en agresión la acción en defensa de su integridad territorial. Esa terminología se emplea ya en Cataluña. Los actos de ilícita injerencia se transforman en asistencia en la legítima defensa del Estado nuevo. Cierto es que cuando se reconoce como Estado soberano a quien no es un Estado efectivo se incurre en responsabilidad internacional, pero las reclamaciones pueden acabar siendo hechas al maestro armero, especialmente si el Estado reconocido consolida su efectividad en el curso de los acontecimientos. 
Por lo que se refiere a los miembros de la UE, ha de señalarse que la independencia de Cataluña no solo la convertiría en Estado tercero a la Unión, sino que su reconocimiento por uno o más de ellos supondría una infracción grave de sus obligaciones conforme a los tratados constitutivos de la Unión, en particular del art. 4.2 del TUE. Las simpatías que a nivel parlamentario, social o mediático, hayan podido despertar los independentistas catalanes en los países bálticos, nórdicos o procedentes de la antigua Yugoslavia, no tendrá traducción a nivel de reconocimiento. Las instituciones de la Unión han cerrado la puerta al Sr. Puigdemont, ambulante, tuiteante y teleparlante por Bruselas. Cabe, sin embargo, pronosticar que no solo estos países, sino la generalidad de los miembros de la Unión y sus instituciones presionarían a España para que asumiera un diálogo abierto con los independentistas catalanes si logran una cierta efectividad y el Estado es incapaz de hacerse con la situación en un plazo razonable.

18 de diciembre de 2017

Palabras clave: Cataluña, secesión, libre determinación, declaración de independencia, art. 155 de la Constitución española, euroorden, reconocimiento.

Keywords: Catalonia, secession, self-determination, declaration of independence, article 155 of the Spanish Constitution, european arrest warrant, recognition. 